\title{
Video Article \\ Manipulation of Color Patterns in Jumping Spiders for Use in Behavioral Experiments
}

\author{
Malika Ihle ${ }^{1}$, Lisa Anne Taylor ${ }^{1,2}$ \\ ${ }^{1}$ Department of Entomology and Nematology, University of Florida \\ ${ }^{2}$ Florida Museum of Natural History, University of Florida \\ Correspondence to: Malika Ihle at malika_ihle@hotmail.fr
}

URL: https://www.jove.com/video/59824

DOI: doi:10.3791/59824

Keywords: Environmental Sciences, Issue 147, jumping spider, face-painting, color manipulation, aposematic, foraging, cannibalism, eyeliner, enamel paint, arthropods, insects

Date Published: 5/21/2019

Citation: Ihle, M., Taylor, L.A. Manipulation of Color Patterns in Jumping Spiders for Use in Behavioral Experiments. J. Vis. Exp. (147), e59824, doi:10.3791/59824 (2019).

\section{Abstract}

In the field of behavioral ecology, many experiments are designed to investigate the evolutionary purposes of colorful traits in the context of sexual selection and predation. Methods are various but mostly consist of modifying the color patterns of individuals with diverse colorants. Such techniques have been used across many vertebrate taxa, particularly in birds, but have remained underdeveloped for invertebrates because of the difficulty of effectively manipulating color in small organisms. Instead, to manipulate the appearance of invertebrates, scientists have usually modified the lighting environment to filter out certain wavelengths. However, such a method affects not only the phenotypic trait of interest but the entire appearance of the individual and its surrounding. Here, scaling down the techniques previously used on colorful birds, we present ways of manipulating the colors of small arthropods, using equally emblematic but understudied species: the colorful jumping spiders.

\section{Video Link}

The video component of this article can be found at https://www.jove.com/video/59824/

\section{Introduction}

Animals often have elaborate color patterns that they display during sexual encounters, agonistic encounters, or to deter predation. These traits may convey information to receivers such as the signaler's individual quality as a mate ${ }^{1}$, fighting ability as a competitor ${ }^{2}$, or palatability as a prey item $^{3}$. To understand the adaptive purposes of colorful traits, researchers have designed experiments that involve manipulating colors in various ways. Some researchers have used colored decoy stimuli such as models ${ }^{4,5,6,7,8}$, photographs ${ }^{9}$, or videos ${ }^{10,11,12}$ that are presented to receivers in behavioral experiments. Others, especially when using invertebrates, have manipulated the lighting environment to affect the appearance of colors of live individuals ${ }^{13,14,15,16,17}$. All these manipulations, while ingenious, have the disadvantage of removing potentially important natural behavior and/or affecting much more than the trait of interest. In large vertebrates, such as birds, researchers very often manipulate color directly on live animals (reviewed in Hill and McGraw, $2006^{18}$ ). Individual feathers or beaks have been directly colored with markers ${ }^{2,19,20,21,22,23,24}$, dyes containing hydrogen peroxide often used in hair lighteners ${ }^{25,26,27}$, or various paints including nail polish ${ }^{28}$. In invertebrates, such studies that manipulate color patterns directly on live animals are comparatively rare but have still provided immense insight into the function and evolution of color $29,30,31,32,33,34,35,36,37,38,39$. Even arthropod studies seem to be biased towards larger taxa that can be more easily handled and painted, leaving color patterns in very small species relatively understudied.

Here, we describe a delicate color manipulation technique that was developed for very small animal taxa. Specifically, this method involves manipulating the facial coloration of male jumping spiders under a microscope in order to investigate the importance of such colorful traits in the context of mate choice and sexual cannibalism. In this case, we used Habronattus pyrrithrix (collected from Phoenix, AZ, USA) as a model species (Figure 1). We have published the results of experimental work using some of these techniques elsewhere ${ }^{38,39}$, but here we describe the methods in more detail than has been done previously, in a way that should make them accessible to others attempting to replicate them or adapt them for use on other very small taxa. Such protocols should open up experimental opportunities on animals that can be as colorful as the most emblematic birds but that are usually understudied.

\section{Protocol}

\section{Equipment preparation}

1. Select appropriate paints. 
1. For successful application, use paints that are quick-drying and have a texture that is easily manipulated with thinner. Products that have been used successfully include non-waterproof eyeliners which can be thinned with water, and enamel paints which can be thinned with enamel thinner (Table of Materials).

2. When painting spiders, consider that the carapace of most species has a hardened exoskeleton while the soft abdomen often stretches and constricts with feeding ${ }^{40}$.

1. Enamel paints produce a solid, hardened coating on the painted surface; therefore, apply them on hard parts of the cuticle (e.g., carapace, legs, pedipalps). Such enamel coatings are less effective for spider abdomens because they peel off of the spider as the abdomen changes shape with feeding.

2. In contrast, eyeliners do not produce a hardened coating, but rather seep into the colored body scales; as such, use them on both hard and soft body parts (including spider abdomens).

NOTE: In the upcoming steps, the most delicate technique is presented that consists of painting the face and pedipalps of the spiders; enamel paint is used, which is the most generalizable method due to the color diversity of enamel paint available.

3. Before testing paints on live animals, if possible, first measure the spectral properties of the paint (simply applied to paper or another surface) using a UV-VIS reflectance spectrophotometer to ensure that there are not any unwanted UV peaks in the spectrum that would be invisible to humans, but possibly visible to the studied species.

2. Use a dissecting microscope connected to a camera and a computer to more easily take pictures of the outcome of the manipulation for documentation and increasing replicability (Table of Materials).

1. Turn on the microscope, computer, and software that processes the camera input.

2. Select the relevant zoom at which the final picture will be taken.

3. Stick an insect mounting pin or a small nail (with the head pointed outwards) into a ball of non-hardening modeling clay (approximately the size of a grape). (The live spider to be painted will be temporarily mounted to the head of this pin in step 3.1 below). Place the modeling clay and pin under the microscope to adjust the objectives so that they roughly focus on the head of the pin (where the spider is to be mounted).

4. Make sure the objectives are at the right distance for the painter's eyes, and that the camera is not obstructing the field of vision during painting (as is the case if the camera is mounted in one of the oculars, hindering depth perception).

3. Transfer the spider into a clean plastic snap-cap vial (around 12 drams, without any webbing or dead prey).

4. Prepare mounting and painting equipment.

1. Place an extra thin insect mounting pin into a ball of non-hardening modeling clay (in addition to the one used in Step 1.2.3) and place them on the left side of the microscope (for right-handed people). This pin will be used to gently adjust the positions of the spider's legs and pedipalps (as needed) during painting.

2. Get a small piece of absorbent paper (such as a paper towel), a piece of white printer paper, the paints to apply (here, enamel paint), separate containers of paint thinner (one for each color plus one kept transparent and clean), individual micro brushes for each color (see Table of Materials), and one micro brush to be only used with clean thinner, all positioned in an organized fashion on the right of the microscope (for right-handed people).

3. Using a toothpick, add a drop of paint in an open plastic dish (such as a small Petri dish or a vial cap) and add paint thinner, for instance with a small syringe. Mix the two with the toothpick to the right consistency (when the paint is completely homogenized, but not too runny) by testing it on the white printer paper with a micro brush.

NOTE: In certain cases, if the paint dries quickly, prepare it with slightly more liquid than desired for application, and let the brushes soak in the pot of paint thinner until later use (step 4).

4. Put a pea-sized drop of water-based glue (see Table of Materials) onto a corner of the printer paper.

NOTE: This must be the last stage of the preparation and the next step needs to happen immediately after this, so that the glue does not dry out.

\section{Anesthetizing the spider}

1. With the spider in the vial and a hand cupped over the opening to prevent escape, slowly add $\mathrm{CO}_{2}$ gas until the spider's third pair of legs extends to 180 degrees.

2. Use a time of exposure to $\mathrm{CO}_{2}$ of approximately 20 seconds to 1.5 minutes, depending on the average size of the species and on the individual spider. We have found the extension of the third pair of legs to be a reliable indicator of the proper level of anesthesia in $H$. pyrrithrix, but this likely varies across species. If using these techniques with a different species for the first time, first test the anesthesia on a few specimens to assess their response.

3. Give spiders as little $\mathrm{CO}_{2}$ as possible to achieve the needed level of anesthesia. While the short periods of anesthesia described here produced no mortality (and no noticeable behavioral differences from non-anesthetized spiders), give all animals in an experiment equal levels of anesthesia (including sham controls).

4. Keep the vial closed after adding $\mathrm{CO}_{2}$ to maintain the spider under anesthesia; therefore, include this time when calculating how long the spider is exposed to $\mathrm{CO}_{2}$.

5. Once the spider has been removed from the vial to begin color manipulation, it will stay fully anesthetized for approximately 1 to 2 minutes; therefore, do the following steps (sections 3-6) promptly. Because of this limited time window, attempt the following painting method with dead specimens first (for practice) before attempting to paint live spiders.

\section{Mounting the spider under the microscope}

1. Add a very small amount of glue onto the head of the mounting pin or nail in the modeling clay prepared in the field of vision of the microscope. 
NOTE: Use the smallest amount of glue that allows maintaining the spider in place to ensure that i) the spider does not slide off the pinhead (if too much glue is used), and ii) the spider manages to free itself after waking up.

2. Gently slide the anesthetized spider from its vial onto the table with its ventral side up.

NOTE: Because spiders' abdomens are soft, care should be taken not to tap or drop the spiders onto the table, as this may cause injury.

3. Gently press the pinhead (with glue) on the spider's sternum (the central area where the spider's legs attach to the body) such that the spider will slightly bounce and extend its legs under the small pressure applied. For extra control of the pressure applied, hold the modeling clay with both hands, having both hands steadied firmly against the table.

4. Reposition the modelling clay under the microscope so that the area to paint is facing up and in focus.

\section{Painting the spider}

1. Assess the paint consistency prior to touching the paintbrush to the spider

1. Retest the paint consistency (use the absorbent paper to wipe the brushes if they were maintained in the thinner), adjust again if necessary, and always first try applying paint on the printer paper to control for the paint quantity contained in the brush hairs.

2. With the right hand and while looking through the microscope, bring the tip of the brush in the field of vision, and make sure (a second time) that the brush hairs do not contain too much paint, in which case wipe some of it onto the printer paper.

2. Test the paint consistency on the spider.

1. Touch the spider with the brush on the largest area that will need to be painted over. This will inform the painter whether the consistency and quantity of paint is right (i.e., when the paint slightly and slowly soaks into the hair/scales of the spider).

1. If no paint gets applied, soak the brush into the paint and return to step 4.1 to repeat the procedure.

2. If the paint soaks in rapidly and spills over onto an area that should not be covered by paint, and assuming that the spillage is minimal and that the individual could still take part in the experiment, wipe the brush onto the absorbent paper and return to step 4.1 to repeat the procedure.

NOTE: This type of liquid spillage cannot be fixed. If the spillage reaches the chelicerae or the eyes, or other parts that could be lethal or toxic for the individual, consider placing the spider immediately in the freezer to euthanize it before it wakes up and excluding the spider from the experiment.

3. Paint all areas that need colors following steps 4.1 and 4.2 .

1. If painting the face of the spider, use the extra thin pin with the left hand to hold down the front legs and pedipalps (so that they will be out of the way of the paintbrush). This is best done while looking through the microscope to avoid damaging the spider's appendages. In addition, if painting the face of the spider, and depending on the brushes used to paint, consider painting both sides of the face before trying to paint the central part between the eyes-both painted areas can be joined by holding the brush parallel to the spider face and inducing capillary action.

NOTE: When painting the face of the spider, it is easiest to first paint the side nearest the dominant hand, and then rotate the ball of clay (with the mounted spider) around under the microscope to paint the other side, followed by the middle.

2. When painting pedipalps or legs, make sure not to touch any joints if the paint is a hardening one (such as the enamel paint), and make sure not to apply paint to the male's sperm delivery organs (on the underside of the distal segment of the pedipalps).

\section{Taking the spider's picture}

1. Switch the objective to the camera mode.

2. Take a picture using the computer software, making sure the zoom picked is the one selected on the microscope, so that a scale bar can be added.

\section{Releasing the spider from the pin or nail}

1. When the spider starts moving, hold the pin so that the spider's front legs are touching the spider's vial.

2. Let the spider release itself, and if needed, gently incline the pin to help the spider pull itself away from the dried glue.

1. If the spider wakes up before the painting is completed, allow the spider at least 15 minutes to recover before being anesthetized again. If this is done, ensure that all groups get the same levels of anesthesia (including sham-treated individuals, if applicable). NOTE: Spiders appear to resume their normal behavior rapidly after manipulation $(<15 \mathrm{~min})$ but we recommend a standardize resting time of 12 hours prior to using the spider in a behavioral test.

\section{Analysis of the spiders' behavior}

1. Compare the behavior of unmanipulated, sham-treated, and manipulated subjects to assess the potential toxicity of the application (which may vary by specific paint type, color, application area, and study species). Relevant behavior to compare could include activity rate, type of activity performed, success in performing specific activities (e.g., capturing prey), etc.

1. Use sham-treated spiders as part of the experimental design (for instance receiving the paint application on a non-visible area or having neutral-colored paints applied to the same areas) in order to only change the color of the individual while controlling for other factors (e.g. handling time, odor, surface texture, etc.).

NOTE: If painting legs or pedipalps, consider the possibility that this may interfere with sensory hairs (prevalent on spider legs and pedipalps, see Foelix $2010^{40}$ ) and, in these cases sham-treated males should have neutral-colored paints applied to the same areas as a control. 
2. When developing new methods, compare painted spiders with unmanipulated spiders to assess whether color-manipulated individuals still behave normally.

\section{Measuring the reflectance properties of the color manipulation on the painted subject}

1. Once euthanized (after spiders were involved in an experiment or specifically euthanized for this purpose, see Note below), measure the spectral properties of the color manipulation using a standard portable UV-VIS spectrophotometer (Table of Materials), especially for areas larger than $1 \mathrm{~mm}$ in diameter.

2. For smaller areas, use a custom-built microspectrophotometer (a UV-VIS spectrophotometer routed through a microscope) for easier and more precise measurements, although the optics of the microscope cut out UV light, meaning that measurements are limited to the humanvisible wavelengths (see Taylor et al. $2011^{41}$ ).

3. In cases where color-manipulated areas are extremely small and UV reflectance data are required, use commercially available UV-VIS microspectrophotometers, although they are more expensive (see Taylor et al. $2014^{42}$ ).

NOTE: The light source of UV-VIS spectrophotometers contains UV light and can be dangerous to animals' eyes (including ours) so spectral measures should only be done after the animals are euthanized and not merely anesthetized. For enamel-painted spiders, this can be done after the spiders have been used in experiments since the paint does not wear off (see representative results below). For water-based paint which may sometimes fade after days or weeks, a set of spiders could be sacrificed for measurement at the time when their counterpart would be involved in an experiment (to capture data that reflects the actual color manipulation used in the experiment). Reporting the spectral properties of the paints will allow replication by other researchers who may want to replicate the color manipulation, but do not have access to the same specific paint products.

Representative Results

Effectiveness of color-manipulation

Using these techniques, various degrees of color manipulation are effective, including concealing colors completely or reducing or enhancing their intensity. This is evident from both photographs and measurements of spectral reflectance (Figure 2, Figure 3, and Figure 4). Here we show color-manipulated male Habronattus pyrrithrix compared to natural red-faced males. Spectral properties were measured using a UV-VIS spectrophotometer (see Table of Materials) that can precisely measure colored areas as small as $1 \mathrm{~mm}$ in diameter. Measurements were taken relative to a diffuse reflectance white standard (see Table of Materials).

On rare occasions ( 5 out of 108 males painted with black eyeliner 1 (see Table of Materials) on their face), the water-soluble eyeliner began to wear off the spiders' faces after a week or two. This was not observed for the other brand of eyeliner (eyeliner 2; see Table of Materials). In both cases, spider's cages were sprayed with water three to five times per week. Different conditions of maintenance may affect the wear of waterbased paint. The enamel paint was still intact for all manipulated males ( $n=221)$, even for those still alive after 6 months.

\section{Potential toxicity of the color manipulation}

One should avoid getting paint on the spiders' eyes so as not to obstruct their vision, nor on their chelicerae, mouth parts and other orifices, and possibly other soft body parts to prevent possible ingestion and poisoning. One should also be careful with painting joints or parts that contain sensory hairs (such as the legs and pedipalps) so as not to restrict their mobility or sensory system. However, if such color manipulations on these body regions are necessary, or if there is any doubt about the possibility of subtle negative effects, it is then best to apply paints to individuals in all treatment categories. This way, one would avoid unintentionally manipulating the sensory systems of individuals in ways that might be biased against one of the treatments only. For instance, in an experiment using males manipulated shown in Figure 4, the aim was to increase and decrease the number of red patches displayed by males during courtship. Since some males would get their natural red faces concealed with gray enamel paint (to decrease the amount of red displayed), the other males for which we wanted to maintain a red face were painted red over their naturally red face with the same product as the gray-faced males. Similarly, since we wanted to add red patches to the pedipalp on certain males to increase the amount of red color patches displayed, gray paint was used to cover the pedipalp of other males so that all males would be painted on this sensitive area (see Figure 4). Although preferable, this strategy may not always be feasible. For instance, in another experiment, the red coloration was removed by using a black eyeliner giving the same spectral property as the underlying cuticle of the male, while leaving the other male colors intact and natural (Figure 2). In this case, for natural looking males, the same amount of eyeliner was applied to the area on the top of their carapace just behind their anterior median eyes (an area that is not clearly visible to females), to control for potential odor or overall toxicity of the product. However, the location where the paint is applied may affect spiders differently. Therefore, to assess subtle differences in the way or the location where the paint was applied may have on the integrity of the spider, the behavior of both types of males in a context that was relevant to our hypotheses (relative to mate choice and sexual cannibalism) was compared. Males were put two-by-two in the presence of a female, and we compared their delay to become active, their delay to courting, and the total duration they spent courting with general linear mixed effect models (using the function Imer with the R package Ime $4^{43}$ in $R$ version $3.5 .2^{44}$ with the female identity as a random effect, and using the maximum likelihood criterion to obtain p-values). In this case, all comparisons reveal no differences between treatments (see Table 1) and it was therefore concluded that we did not introduce a bias in favor of one or the other treatment category. 
In either case, when having very similar treatment categories (Figure 4), or only sham treated individuals (Figure 2 and Figure $\mathbf{3}$ ), researchers should assess how their model species are affected by the paint they use and ensure that they still behave in a similar and ecologically relevant manner. One could record data to assess the possible effects of toxicity as much as possible, for instance by comparing activity rates between treated and unmanipulated individuals. Our spiders painted with enamel paint like in Figure $\mathbf{4}$ were compared to unmanipulated males in an otherwise identical context. Specifically, males were introduced singly to a female cage and their delay to leave the vial, delay to courting and courting rate (prior to copulation, and prior to being attacked or cannibalized) were compared. No differences were found (when using similar linear mixed effect models as above) and we therefore concluded that our painted males behaved naturally (Table 2).

Finally, it is important to note that any spiders in the experiments (usually females) that cannibalized color-manipulated males never appeared to suffer from negative effects. Spiders digest their prey externally, usually leaving the painted areas of the cuticle behind. However, if adapting this method for other systems where color-manipulated animals will be consumed, one should assess the potential risks of toxicity.

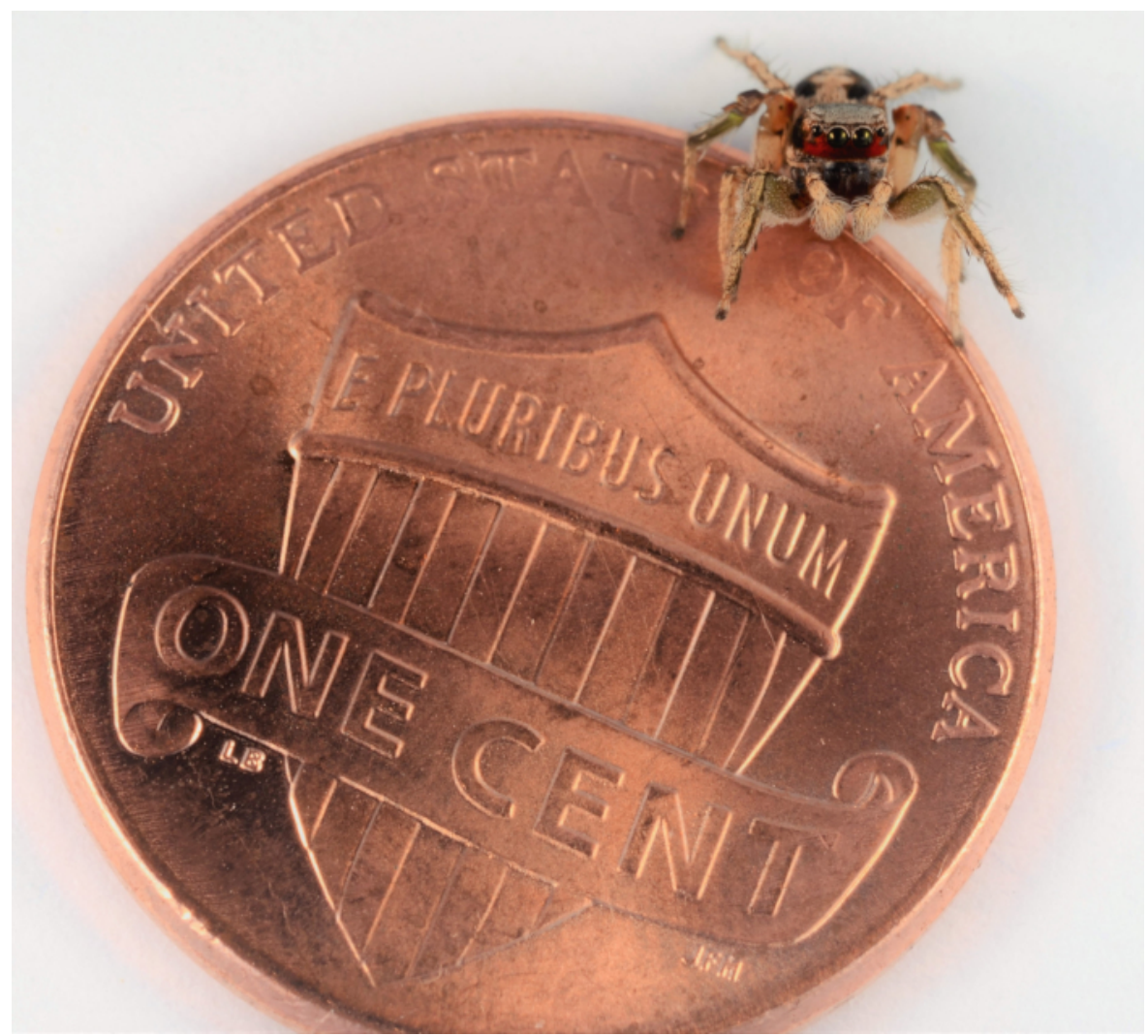

Figure 1. Adult male Habronattus pyrrithrix illustrating how tiny their colored body regions are. Photographed by Lyle Buss. Please click here to view a larger version of this figure. 

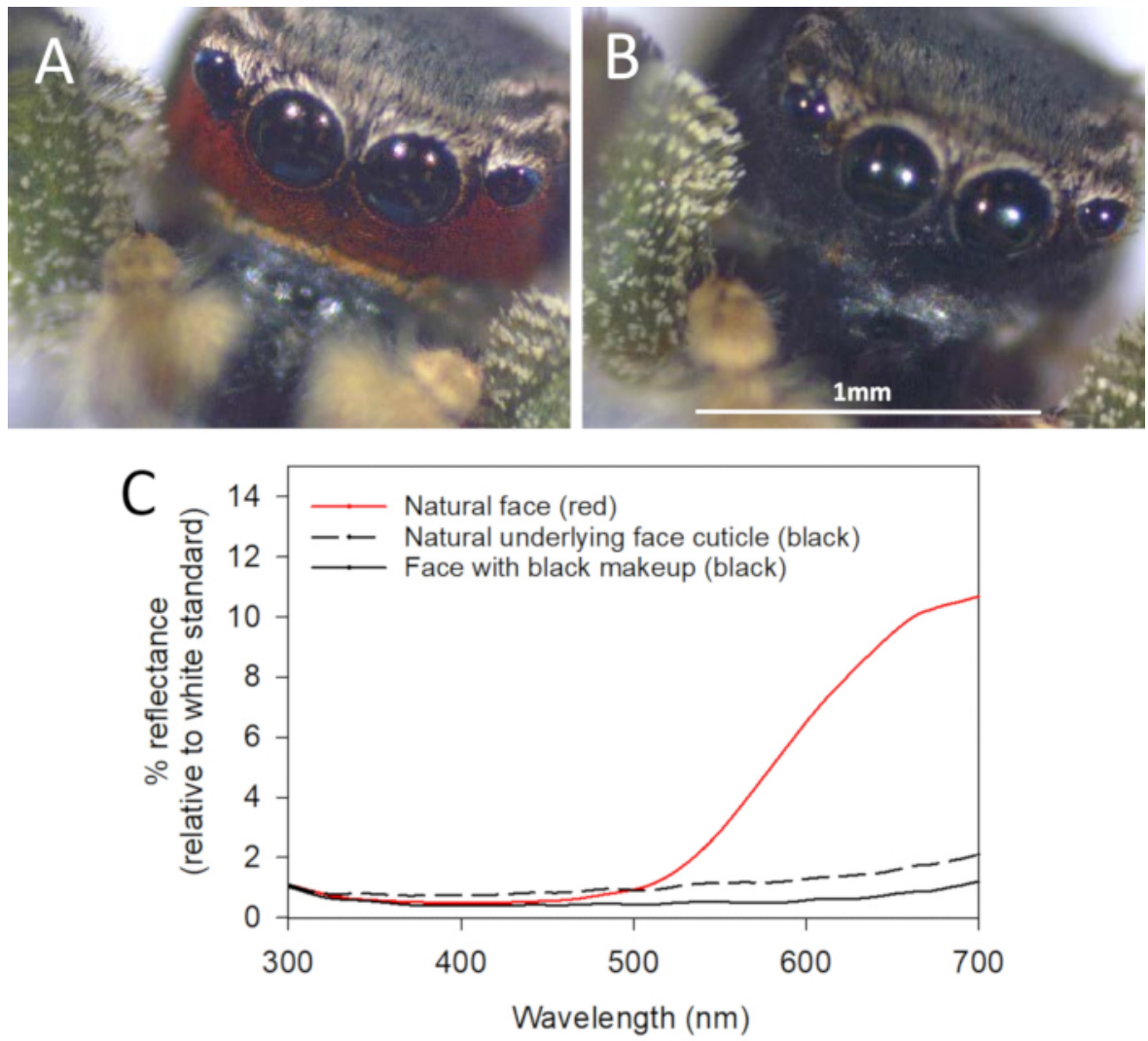

Figure 2. Experimental color manipulation used to conceal red facial coloration in Habronattus pyrrithrix. (A) The intact red facial coloration before color manipulation. (B) The facial coloration of the same male after concealing the natural red coloration with black eyeliner 1. (C) Representative reflectance spectra for the natural red face, the natural underlying black cuticle, and the red face painted with black eyeliner 2. Modified from Taylor and McGraw $2013^{39}$. Please click here to view a larger version of this figure. 

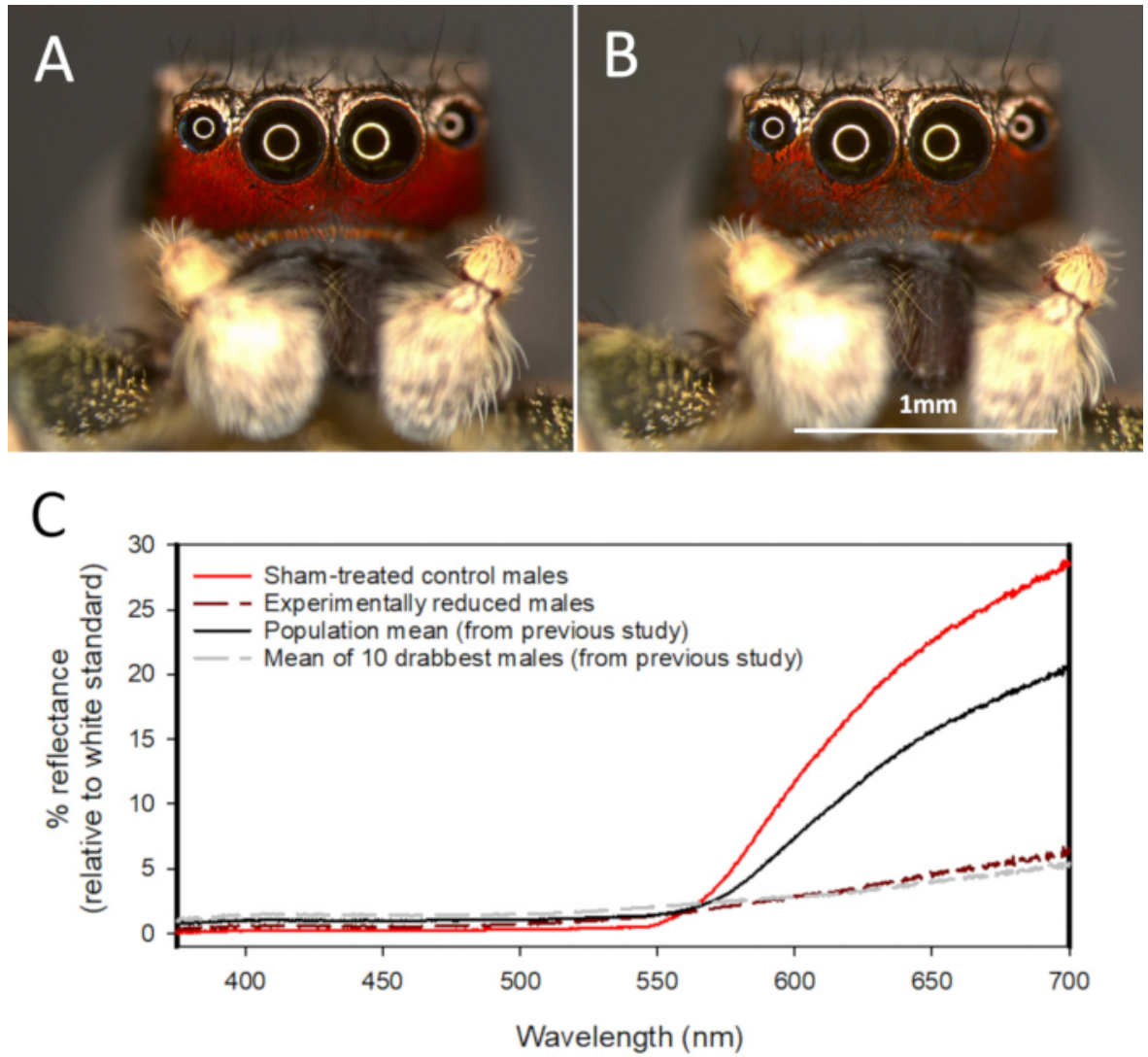

Figure 3. Experimental color manipulation used to reduce the size and redness of the red facial patch of male Habronattus pyrrithrix. (A) The intact red facial coloration before color manipulation. (B) The facial coloration of the same male after applying diluted black eyeliner (Urban Decay) to the front part of the face, and non-diluted black eyeliner along the edges of the facial patch to reduce the size of the red area. (C) Mean spectral curves of sham-treated control males $(n=21)$ and color-manipulated males $(n=21)$, compared with the population mean $(n=57)$ and the 10 drabbest males from a previous study ${ }^{41}$. Figure reproduced from Taylor et al. $2014^{38}$. Please click here to view a larger version of this figure. 


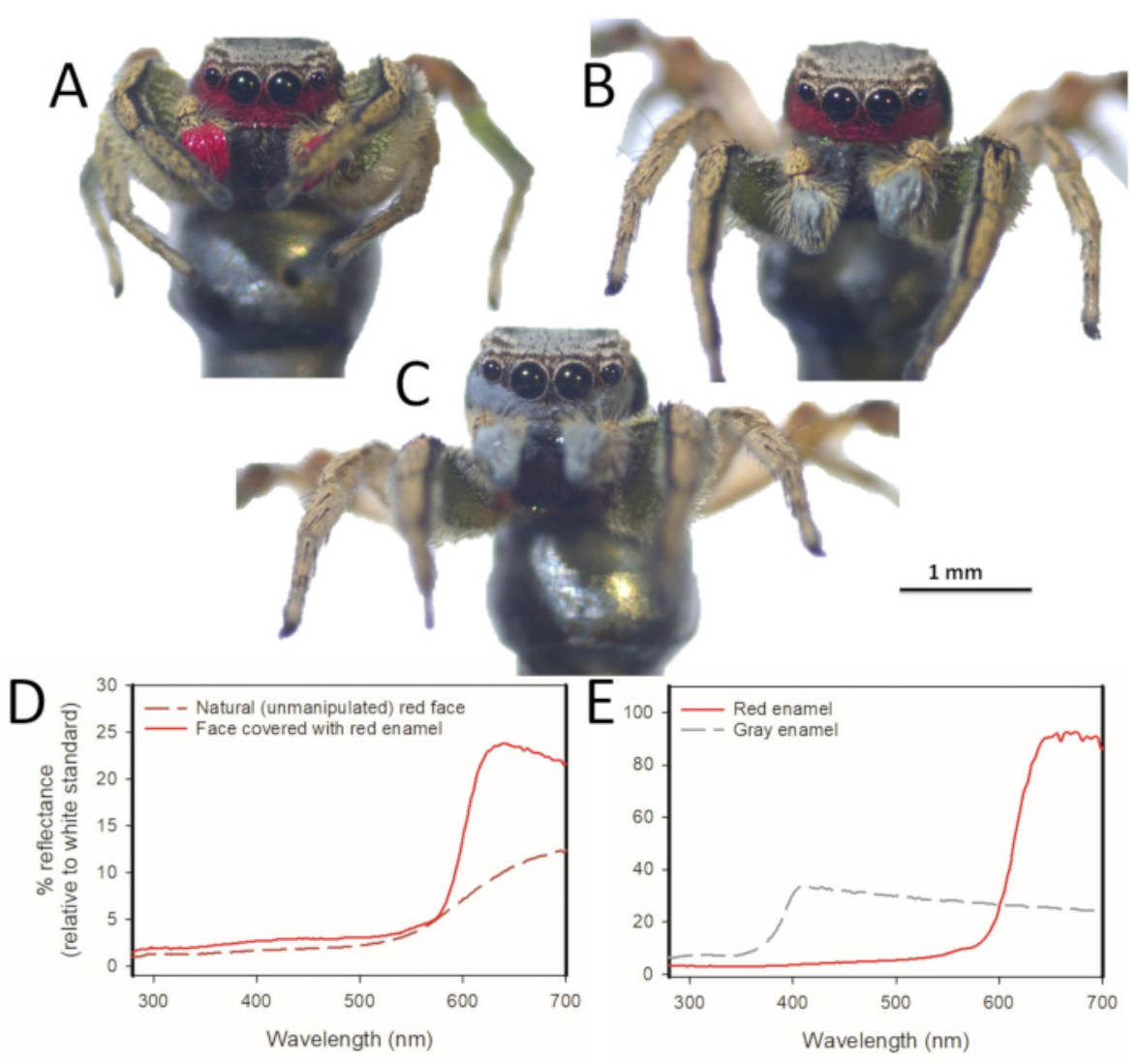

Figure 4. Experimental color manipulation used to modify the color of the red facial patch of male Habronattus pyrrithrix. Habronattus pyrrithrix males painted with (A) red, (B) red and gray, and (C) gray enamel paint over their natural red face and naturally cream-colored pedipalps. (D) Mean spectral curves for unmanipulated males $(n=9)$, and males with their face covered with red enamel paint $(n=9)$. By applying a brighter red over the spider's face, we effectively enhanced its red facial coloration. Because enamel paint fully covers the underlying scales, color could also be changed entirely, as is the case with the gray enamel. (E) In this experiment, red and gray enamel paints were chosen to be matched for total brightness (total reflectance over the range of wavelengths visible to these spiders). Differences in the scale of the $Y$-axes in $D$ and $E$ are due to different techniques (such as distance to the sample and size of areas measured) for measuring color samples on paper (E) vs. direct measurements of colors on the face of the spider (D). Please click here to view a larger version of this figure.

\begin{tabular}{|l|l|l|l|l|l|l|l|l|}
\hline $\mathrm{N}$ & $\begin{array}{l}\text { Dependent } \\
\text { variable }\end{array}$ & $\mathrm{p}$ & $\mathrm{t}$ & Red-faced & \pm SE & Black-faced & \pm SE & $\mathrm{nFID}$ \\
\hline $202_{\mathrm{b}}$ & $\begin{array}{l}\text { Male delay to } \\
\text { leave dish }\end{array}$ & 0.35 & -0.93 & 140.0 & 23.9 & 109.8 & 23.9 \\
\hline $179_{\mathrm{c}}$ & $\begin{array}{l}\text { Male delay to } \\
\text { court }\end{array}$ & 0.74 & 0.33 & 983.4 & 127.1 & 1031.0 & 126.5 & 102 \\
\hline $204_{\mathrm{a}}$ & $\begin{array}{l}\text { Male courtship } \\
\text { effort }\end{array}$ & 0.52 & 0.63 & 181.2 & 24.4 & 203.0 & 24.4 \\
\hline $204_{\mathrm{a}}$ & $\begin{array}{l}\text { Male courtship } \\
\text { effort prior to } \\
\text { any attack }\end{array}$ & 0.41 & 0.68 & 89.0 & 15.7 & 97.5 & 102 \\
\hline
\end{tabular}

Table 1. Effect of male face color manipulation on behavior, when painted with black eyeliner vs. sham treated (Figure 2). The structure of each model is given, as well as the mean estimates in seconds ( \pm SE) for each treatment group. $N=$ number of males, $p$ and $t=p$-value and $t-$ value for the male treatment, $\mathrm{nFID}=$ the number of levels in the random effect female identity. ${ }^{\mathrm{a}}$ Out of the 104 male tests performed, 102 were successfully recorded, leading to 204 unique males observed. ${ }^{b} 2$ males were cannibalized by the female prior to ever exiting the petri dish. ${ }^{c} 25$ males were cannibalized by the female prior to ever courting the female. 


\begin{tabular}{|l|l|l|l|l|l|l|l|}
\hline $\mathrm{N}$ & $\begin{array}{l}\text { Dependent } \\
\text { variable }\end{array}$ & $\mathrm{p}$ & $\mathrm{t}$ & Unmanipulated & $\pm \mathrm{SE}$ & Painted & $\pm \mathrm{SE}$ \\
\hline $32_{\mathrm{a}}$ & $\begin{array}{l}\text { Male delay to } \\
\text { leave dish }\end{array}$ & 0.87 & -0.17 & 380.8 & 143.1 & 345.4 & 152.4 \\
\hline $31_{\mathrm{b}}$ & $\begin{array}{l}\text { Male delay to } \\
\text { court }\end{array}$ & 0.93 & -0.09 & 502.6 & 105.8 & 488.1 & 116.6 \\
\hline $31_{\mathrm{b}}$ & $\begin{array}{l}\text { Male courtship } \\
\text { effort }\end{array}$ & 0.74 & -0.33 & 2324.3 & 455.0 & 2102.1 & 484.4 \\
\hline $31_{\mathrm{b}}$ & $\begin{array}{l}\text { Male courtship } \\
\text { effort prior to any } \\
\text { attack }\end{array}$ & 0.68 & 0.42 & 1495.1 & 450.8 & 1770.1 & 479.9 \\
\hline
\end{tabular}

Table 2. Effect of male face color manipulation on behavior, when painted with red or gray enamel paint $(n=15$, Figure 4) vs. unmanipulated males $(n=17)$. The structure of each model is given, as well as the mean estimates in seconds $( \pm S E)$ for each treatment group. $N=$ number of males, $p$ and $t=p$-value and $t$-value for the male treatment. ${ }^{a} 17$ unmanipulated males were compared to a subset of all the painted males in our experiment $(n=221)$. Specifically, they were compared to 15 painted males ( 5 red (Figure $2 A), 5$ red and gray (Figure 2B), and 5 gray (Figure 2C)) tested in the same context (in presence of a female) and in the same specific time period. This is important because unmanipulated males were tested towards the end of the experiment (in August and September 2018), which corresponds to the end of their natural breeding season and where males are generally less active. Keeping all these other variables equal allows us to compare the painting treatment without introducing other biases. ${ }^{b}$ One male (all gray) was cannibalized prior to ever courting the female.

\section{Discussion}

Here, we show that the colors of tiny body parts of arthropods can effectively be manipulated using colorants such as makeup and enamel paints.

The first critical step to achieve such delicate manipulation is to be able to immobilize small animals that usually cannot be restrained in one's hand. Here, to be able to paint sensitive areas such as jumping spider's face, we anesthetized individuals with $\mathrm{CO}_{2}$ and mounted them on the head of a pin. This allows work close to the spider's eyes with less stress than the spider would likely experience if it were awake (with light from the microscope shining into their faces during the painting process).

The method also requires getting good quality micro brushes, and, most critically, appropriate coloring substances. The most difficult step in applying paint without spillage but with good coverage is to get the right consistency. Therefore, the coloring substances need to be easily diluted with a thinner, and easily dried out for thickening. Different type of paints could be used; here, the results are presented with water-soluble (non-waterproof) eyeliners and enamel paints. Non-waterproof eyeliners have the advantage of being easily liquefied when mixed with water. However, this trades off with the dilution of the pigmentation (which may not or may be desirable (see for instance Figure 3)). Enamel paints have a consistency that can easily be controlled by adding enamel thinner, while still providing full coverage. However, this characteristic trades off with the possibility of maintaining the hair or scale structure of the body part painted. In addition, enamel paints are long lasting. The downside to this is that enamel paint and thinner emit strong odors during application and before drying. One additional difficulty regarding the coloring substances may be to find the right shade, with the right spectral properties. It is for instance hard to get red eyeliner to use in parallel with black eyeliner, as eyeliners are often more pink than red. It is also hard to get makeup powder (or pigments) that do not contain any glitter (which can sometimes be only visible under the microscope). Many makeup products also reflect UV light which, while invisible to the experimenters, might be conspicuous to the animals studied.

Manipulating the coloration of arthropods by directly applying colorants onto their body parts comes with advantages and inconveniences when compared to other methods. Its main limitation is that one cannot absolutely dismiss the possibility of some subtle toxicity effects. However, one can ensure not to introduce biases against one treatment group by applying paint to all treatment categories, and/or one can test whether the paint application interferes with behaviors of interest. With the methods presented here, we collected enough evidence to suggest that the paint application led to negligible to no negative effect (Table 1 and Table 2). The main advantage of this method is that tiny patches of color can be targeted, their color 'removed' (see Figure 2), made duller (Figure 3) or brighter (Figure 4), in isolation from the rest of the body coloration and the individual's environment. This contrasts with the most common alternative method which consists of manipulating the lighting conditions, and thereby modifying the visual appearance of the whole individual and its surroundings. In fact, even when not specifically manipulating lighting conditions, one can successfully manipulate color and see limited or no effects of this manipulation if the lighting environment is not appropriate $^{39}$. Therefore, it is important to measure and consider the light environment where any experiments will be conducted (i.e., measure irradiance) and make sure to closely match it to natural lighting conditions (for instance using full spectrum light bulbs that mimic natural light when in captivity). Overall, by using micro brushes and a microscope, this protocol allows for more precise manipulation of tiny color patches than most other direct coloring methods that have been used previously on invertebrates. Most previous studies have used animals with color patches that are relatively large compared to the faces of jumping spiders (e.g., manipulation of butterfly wing colors ${ }^{29,34,35}$, the bodies of adult hemipterans ('true bugs') ${ }^{30,36}$ and grasshoppers ${ }^{31}$, or the legs of relatively large wolf spiders ${ }^{32,33,37}$ ). The methods presented here open up opportunities to study the amazing diversity of color patches on taxa that are understudied due to their small size.

Similar techniques could be applied to other arthropods that can be immobilized or anesthetized and for areas where paint would not affect the mobility or health of the individual (i.e., excluding areas such as joints, structures such as hair or arolia that are needed for appropriate locomotion, mouth parts, or other orifices such as breathing structures). These techniques can also be extended to include a larger palette of dyes, paints, and makeups that are widely available. 
Finally, these delicate techniques could be used not only to manipulate color on small organisms, but also to manipulate patterns (such as stripes) in relatively larger organisms. This should be beneficial to a wide variety of researchers that can adapt our methods to their own studies of sexual selection, communication, aposematic prey signals, and other contexts in which animals use color.

\section{Disclosures}

The authors have nothing to disclose.

\section{Acknowledgments}

This work was supported by funding from the National Science Foundation (IOS-1557867 to LAT), the Florida Museum of Natural History, and the Entomology and Nematology Department at the University of Florida. Publication fee of this article was funded in part by the University of Florida Open Access Publishing Fund.

\section{References}

1. Baeta, R., Faivre, B., Motreuil, S., Gaillard, M., Moreau, J. Carotenoid trade-off between parasitic resistance and sexual display: an experimental study in the blackbird (Turdus merula). Proceedings of the Royal Society B: Biological Sciences. 275 (1633), $427-434$ (2008).

2. Ninnes, C. E., Webb, S. L., Andersson, S. Are red bishops red enough? On the persistence of a generalized receiver bias in Euplectes. Behavioral Ecology. 28 (1), 117-122 (2017).

3. Mappes, J., Marples, N., Endler, J. A. The complex business of survival by aposematism. Trends in Ecology \& Evolution. 20 (11), $598-603$ (2005).

4. Clark, D. L., Macedonia, J. M., Rowe, J. W., Kamp, K., Valle, C. A. Responses of Galápagos Lava Lizards (Microlophus bivittatus) to Manipulation of Female Nuptial Coloration on Lizard Robots. Herpetologica. 73 (2017).

5. Finkbeiner, S. D., Briscoe, A. D., Reed, R. D. Warning signals are seductive: Relative contributions of color and pattern to predator avoidance and mate attraction in Heliconius butterflies. Evolution. 68 (12), 3410-3420 (2014).

6. Moore, M. P., Martin, R. A. Intrasexual selection favours an immune-correlated colour ornament in a dragonfly. Journal of Evolutionary Biology. 29 (11), 2256-2265 (2016).

7. Nokelainen, O., Valkonen, J., Lindstedt, C., Mappes, J. Changes in predator community structure shifts the efficacy of two warning signals in Arctiid moths. Journal of Animal Ecology. 83 (3), 598-605 (2014).

8. Yewers, M. S. C., Pryke, S., Stuart-Fox, D. Behavioural differences across contexts may indicate morph-specific strategies in the lizard Ctenophorus decresii. Animal Behaviour. 111, 329-339 (2016).

9. Baldwin, J., Johnsen, S. The male blue crab, Callinectes sapidus, uses both chromatic and achromatic cues during mate choice. The Journal of Experimental Biology. 215 (7), 1184 (2012).

10. Künzler, R., Bakker, T. C. M. Female preferences for single and combined traits in computer animated stickleback males. Behavioral Ecology. 12 (6), 681-685 (2001).

11. Landmann, K., Parzefall, J., Schlupp, I. A sexual preference in the Amazon molly, Poecilia formosa. Environmental Biology of Fishes. 56 (3), 325-331 (1999).

12. Nelson, X. J., Jackson, R. R. A predator from East Africa that chooses malaria vectors as preferred prey. PLoS ONE. 1 (1), e132 (2006).

13. Bajer, K., Molnár, O., Török, J., Herczeg, G. Female European green lizards (Lacerta viridis) prefer males with high ultraviolet throat reflectance. Behavioral Ecology and Sociobiology. 64 (12), 2007-2014 (2010).

14. Gerlach, T., Sprenger, D., Michiels, N. K. Fairy wrasses perceive and respond to their deep red fluorescent coloration. Proceedings of the Royal Society B: Biological Sciences. 281 (1787), 20140787 (2014).

15. Girard, M. B., Elias, D. O., Kasumovic, M. M. The role of red coloration and song in peacock spider courtship: insights into complex signaling systems. Behavioral Ecology. 29 (6), 1234-1244 (2018).

16. Lim, M. L. M., Land, M. F., Li, D. Sex-specific UV and fluorescence signals in jumping spiders. Science. 315 (5811), 481 (2007).

17. Xu, M., Fincke, O. M. Ultraviolet wing signal affects territorial contest outcome in a sexually dimorphic damselfly. Animal Behaviour. 101, 67-74 (2015)

18. Hill, G. E., McGraw, K. J. Bird coloration: function and evolution. Vol. 2 pp.137-200 Harvard University Press, (2006).

19. Chaine, A. S., Roth, A. M., Shizuka, D., Lyon, B. E. Experimental confirmation that avian plumage traits function as multiple status signals in winter contests. Animal Behaviour. 86 (2), 409-415 (2013).

20. Hasegawa, M., Arai, E. Experimentally reduced male ornamentation increased paternal care in the Barn Swallow. Journal of Ornithology. 156 (3), 795-804 (2015).

21. Lawes, M. J., Pryke, S. R., Andersson, S., Piper, S. E. Carotenoid status signaling in captive and wild red-collared widowbirds: independent effects of badge size and color. Behavioral Ecology. 13 (5), 622-631 (2002).

22. Quesada, J.et al. Plumage coloration of the blue grosbeak has no dual function - A test of the armament-ornament model of sexual selection. The Condor. 115 (4), 902-909 (2013).

23. Safran, R. J.et al. The maintenance of phenotypic divergence through sexual selection: An experimental study in barn swallows Hirundo rustica. Evolution. 70 (9), 2074-2084 (2016).

24. Tringali, A., Bowman, R. Plumage reflectance signals dominance in Florida scrub-jay, Aphelocoma coerulescens, juveniles. Animal Behaviour. 84 (6), 1517-1522 (2012).

25. Jerónimo, S.et al. Plumage color manipulation has no effect on social dominance or fitness in zebra finches. Behavioral Ecology. 29 (2), 459-467 (2018).

26. Hill, G. E. Plumage coloration is a sexually selected indicator of male quality. Nature. 350 (6316), 337-339 (1991).

27. Wolfenbarger, L. L. Female mate choice in northern cardinals: is there a preference for redder males? The Wilson Bulletin. 111 (1), 76-83 (1999). 
28. ten Cate, C., Verzijden, M. N., Etman, E. Sexual imprinting can induce sexual preferences for exaggerated parental traits. Current Biology. 16 (11), 1128-1132 (2006).

29. Davis, A. K., Cope, N., Smith, A., Solensky, M. J. Wing color predicts future mating success in male monarch butterflies. Annals of the Entomological Society of America. 100 (2), 339-344 (2007).

30. Exnerová, A.et al. Avoidance of aposematic prey in European tits (Paridae): learned or innate? Behavioral Ecology. 18 (1), $148-156$ (2006).

31. Forsman, A., Appelqvist, S. Visual predators impose correlational selection on prey color pattern and behavior. Behavioral Ecology. 9 (4), 409-413 (1998).

32. Hebets, E. A. Subadult experience influences adult mate choice in an arthropod: exposed female wolf spiders prefer males of a familiar phenotype. Proceedings of the National Academy of Sciences. 100 (23), 13390 (2003).

33. Hebets, E. A., Cuasay, K., Rivlin, P. K. The role of visual ornamentation in female choice of a multimodal male courtship display. Ethology. $112(11), 1062-1070(2006)$.

34. Kingsolver, J. G. Experimental manipulation of wing pigment pattern and survival in western white butterflies. The American Naturalist. 147 (2), 296-306 (1996).

35. Morehouse, N. I., Rutowski, R. L. In the eyes of the beholders: Female choice and avian predation risk associated with an exaggerated male butterfly color. The American Naturalist. 176 (6), 768-784 (2010).

36. Prudic, K. L., Skemp, A. K., Papaj, D. R. Aposematic coloration, luminance contrast, and the benefits of conspicuousness. Behavioral Ecology. 18 (1), 41-46 (2006).

37. Rutledge, J. M., Miller, A., Uetz, G. W. Exposure to multiple sensory cues as a juvenile affects adult female mate preferences in wolf spiders. Animal Behaviour. 80 (3), 419-426 (2010).

38. Taylor, L. A., Clark, D. L., McGraw, K. J. Natural variation in condition-dependent display colour does not predict male courtship success in a jumping spider. Animal Behaviour. 93, 267-278 (2014).

39. Taylor, L. A., McGraw, K. J. Male ornamental coloration improves courtship success in a jumping spider, but only in the sun. Behavioral Ecology. 24 (4), 955-967 (2013).

40. Foelix, R. Biology of spiders. Third edn Oxford University Press, (2010).

41. Taylor, L. A., Clark, D. L., McGraw, K. J. Condition dependence of male display coloration in a jumping spider (Habronattus pyrrithrix). Behavioral Ecology and Sociobiology. 65 (5), 1133-1146 (2011).

42. Taylor, L. A., Maier, E. B., Byrne, K. J., Amin, Z., Morehouse, N. I. Colour use by tiny predators: jumping spiders show colour biases during foraging. Animal Behaviour. 90, 149-157 (2014).

43. Bates, D, Maechler, M, Bolker, B, Walker, S. Fitting Linear Mixed-Effects Models Using Ime4. Journal of Statistical Software., 67 (1), 1-48 (2015).

44. R Core Team. R: A language and environment for statistical computing. R Foundation for Statistical Computing. Vienna, Austria. URL URL https://www.R-project.org/ (2018). 